Diabetologia (1994) 37: 337-343

\title{
Originals
}

\section{Evidence of CD4 + regulatory T cells in the non-obese diabetic male mouse}

\author{
P. Sempé, M.-F. Richard, J.-F. Bach, C. Boitard \\ INSERM U25, Hôpital Necker-Enfants Malades, Paris, France
}

\begin{abstract}
Summary The NOD mouse, which shows many features of human IDDM, is extensively used to evaluate the role of T lymphocytes in the pathogenesis of autoimmune diabetes. The development of diabetes in this model appears to be controlled by a finely tuned immunoregulatory balance between autoaggressive $T$ cells and regulatory immune phenomena, the disruption of which may result in destruction of insulin-secreting cells. The absolute requirement of sublethal irradiation to permit transfer of the disease to non-diabetic adult syngeneic mice provides indirect evidence for the presence of regulatory $T$ cells in non-diabetic NOD mice. We have previously reported that the reconstitution of irradiated recipients by CD $4+T$ cells from nondiabetic female NOD mice blocks the transfer of diabetes by spleen cells from diabetic donors. We now
\end{abstract}

report evidence that anti-CD4 monoclonal antibodies can substitute for irradiation in rendering adult NOD male mice susceptible to diabetes transfer by diabetogenic spleen cells. Efficient diabetes transfer can be achieved in non-irradiated adult NOD recipients provided they are thymectomized and CD4 + T-cell depleted prior to the transfer. The role of thymectomy is to limit $\mathrm{T}$ cell regeneration after anti-T cell monoclonal antibody challenge. Our data confirm that regulatory CD4 + T-cells, which efficiently counterbalance diabetogenic cells, are present in adult NOD male animals. [Diabetologia (1994) 37:337-343]

Key words Non-obese diabetic mouse, regulatory T cells, CD $4+\mathrm{T}$ cells, transfer.
The NOD mouse model [1] is characterized by infiltration of macrophages [2] and T cells [3] into pancreatic islets, followed by widespread beta-cell destruction and hyperglycaemia. Therapeutic strategies aiming at T lymphocytes have succeeded in preventing the disease [4-9]. Transfer of CD4 + and CD $8+T$ cells from diabetic animals precipitates the onset of diabetes in neonates [10] and in irradiated adult recipients [11]. $\mathrm{CD} 4+$ and CD8 + T cell clones induce insulitis upon

Received: 16 August 1993

and in revised form: 26 October 1993

Corresponding author: Dr. P.Sempé, INSERM U25, Hôpital Necker-Enfants Malades, 161 rue de Sèvres, F-75743 Paris Cedex 15, France

Abbreviations: FITC, fluorescein isothiocynate; HBSS, Hank's balanced salt solution; IDDM, insulin-dependent diabetes mellitus; IL, interleukin; NOD, non-obese diabetic; TH: T helper. transfer in non-diabetic NOD and in severe combined immuno-deficient recipients; in some studies, they severely damage NOD islets in vivo [12-18].

Some lines of evidence point to regulatory phenomena which are mediated by T cells [19]. Not all NOD mice become diabetic, particularly males, although all animals develop insulitis [1]. Cyclophosphamide induces early and acute diabetes $[20,21]$. Sublethal irradiation is required to transfer diabetes to adult recipients by diabetogenic T cells [11]. Co-transfer of CD4 + T cells from 8-week-old non-diabetic female NOD mice blocks the development of diabetes induced by the transfer of diabetogenic spleen cells [22]. Protective cells are no longer detectable in mice thymectomized at 3 weeks of age [23]. However, the significance of such regulatory $\mathrm{T}$ cells is compromised by the necessity of irradiation prior to transfer, favouring complete redistribution of lymphoid cells in the recipient. We provide new evidence for the existence of 
Table 1. Lymphoid subsets (\%) within the spleen of non-reconstituted mice after different procedures

\begin{tabular}{|c|c|c|c|c|c|c|}
\hline Thymectomy $^{a}$ & T-cell depletion ${ }^{\mathrm{b}}$ & Weeks after depletion & $\operatorname{Ig}^{+c, d}$ & Thy $1^{+}$ & $\mathrm{CD}^{+}{ }^{+}$ & $\mathrm{CD}^{+}$ \\
\hline+ & + & 2 & 69.5 & 3.6 & 3.3 & 0.4 \\
\hline+ & + & 4 & 73.4 & 10.9 & 10.9 & 1.6 \\
\hline+ & + & 6 & 68.9 & 17.6 & 15.6 & 1.9 \\
\hline+ & + & 8 & 61.9 & 19.7 & 18.3 & 2.4 \\
\hline - & + & 2 & 66.9 & 7.9 & 8.7 & 0.7 \\
\hline - & + & 4 & 54.8 & 31.7 & 28.7 & 2.9 \\
\hline - & + & 6 & 49.2 & 32.2 & 29.2 & 4.1 \\
\hline - & + & 8 & 53.1 & 34.4 & 27.8 & 6.8 \\
\hline+ & - & 2 & 51.4 & 19.0 & 16.6 & 6.4 \\
\hline+ & - & 4 & 55.9 & 28.2 & 20.1 & 9.3 \\
\hline+ & - & 6 & 56.2 & 33.3 & 23.2 & 9.0 \\
\hline+ & - & 8 & 45.6 & 31.9 & 24.7 & 9.7 \\
\hline - & - & 2 & 47.2 & 30.1 & 25.1 & 9.1 \\
\hline - & - & 4 & 41.3 & 44.1 & 33.7 & 11.5 \\
\hline- & - & 6 & 39.1 & 44.2 & 34.3 & 11.2 \\
\hline - & - & 8 & 49.4 & 37.8 & 29.2 & 11.3 \\
\hline
\end{tabular}

${ }^{a}$ Thymectomies $(+)$ or sham thymectomies $(-)$ were performed at 3 weeks of age.

${ }^{\mathrm{b}}$ Male NOD mice received at weeks 5 and 6 a single i.v. injection of $250 \mu \mathrm{g}$ of purified GK1.5 (anti-CD4) plus $250 \mu \mathrm{g}$ of purified H35-17.2 (anti-CD8) $(+)$, or saline $(-)$.

radiosensitive regulatory $\mathrm{CD} 4+\mathrm{T}$ cells in prediabetic NOD male mice by demonstrating the CD4 cell depletion may be successfully substituted for irradiation.

\section{Materials and methods}

\section{Animals}

NOD mice were bred in our facilities in specific pathogen-free conditions and checked at 6-month intervals for bacterial, viral and parasitic infections. The spontaneous incidence of diabetes in our colony reaches 45 to $55 \%$ in females and less than $5 \%$ in males by 6 months of age. Mice are considered diabetic when permanent fasting glycaemia is above $17 \mathrm{mmol} / \mathrm{l}$, as determined using test strips and a colometric assay (Haemoglukotest and Reflolux F; Boehringer-Mannheim, Mannheim, Germany). Swiss nude mice used to produce hybridoma ascites were purchased from Iffa-Credo (L'Arbresles, France).

\section{Antibodies}

Ascites from hybridomas 145-2C11 (hamster anti-CD3 IgG) [24], H35-17.2 (rat anti-CD8 IgG2b) [25], 53.6-7 (rat anti-CD8 IgG2a) [26], 172.4 (rat anti-CD4 IgM), YTS191.1 (rat anti-CD4 IgG2b, kindly provided by Dr. L.Chatenoud), GK1.5 (rat anti-CD4 IgG2b) [27] and 30H12(rat anti-Thy1.2 IgG2b) [28]were purified by precipitation with $40 \%$ saturated ammonium sulphate. Hamster IgG was purified on a Protein-A-sepharose column (Pharmacia, Uppsala, Sweden), rat IgG2bon a Spectra-Gel column (Spectrum, Houston, Tx., USA) and rat IgG2a on a Protein-G-sepharose column (Pharmacia). Antibodies used for in vivo treatment were injected i.p. or i. v. in purified from or as precipitated ascites in phosphate buffered saline (Dulbecco's formula, Flow Labs., Irvine, Scotland). Anti-Thy-1, -CD4 and -CD8 monoclonal antibodies all bear a kappa light chain, which enabled detection of coated cells in treated animals by using an FITC anti-rat kappa light chain monoclonal antibody in FACScan analysis.
${ }^{c}$ Results are the averages of two to three mice per group.

${ }^{\mathrm{d}} \mathrm{Ig}^{+}$is for membrane Ig-positive cells.

For a given value, the SEM does not exceed $10 \%$

\section{Immunofluorescence staining procedure}

For immunostaining studies, anti-CD3 monoclonal antibody (145-2C11) was conjugated with FITC (Sigma, St Louis, Mo., USA). FITC-conjugated anti-CD8 (53.6-7) and phycoerythrinconjugated anti-CD4 (GK1.5) monoclonal antibodies were from Becton-Dickinson (Mountain View, Calif., USA), FITC antiThy1.2 (5A8) monoclonal antibody from Caltag (San-Francisco, Calif., USA), FITC goat Fab anti-mouse IgG and FITC anti-rat kappa light chain (LOMK1) antibodies from Biosys (Compiègnes, France). Immunofluorescence staining analysis was performed using a FACScan (Becton-Dickinson) equipped with a $488 \mathrm{~nm}$ argon laser and linked to a Hewlett-Packard computer. For two-colour staining, FITC-conjugated antibodies were first incubated on ice for $20 \mathrm{~min}$ with fresh cells, after haemolysis of erythrocytes, at the appropriate working dilution. The cells were extensively washed with Hank's balanced saline solution (HBSS, Imperial Lab., Hants, UK) supplemented with $5 \%$ heat-decomplemented fetal calf serum (PAA Lab., Linz, Austria) and $0.1 \%$ $\mathrm{NaN}_{3}$ (Merk, Coger, Paris, France), then incubated with secondlayer phycoerythrin-conjugated antibodies. Cell size was determined by forward light scatter; dead cells were excluded on the basis of forward and side-angle light scatter.

\section{Thymectomy}

Thymus ablation was performed under anaesthaesia by suction with a Pasteur pipette [23]. Sham-thymectomized mice were used as controls throughout the study. Total thymectomy was confirmed at autopsy by visual examination and mice with thymic remnants were discarded.

\section{Adoptive transfer of diabetes and cell fractionation}

Non-irradiated NOD recipients were injected i.v. with $10^{7}$ pooled purified $\mathrm{T}$ cells collected from overtly diabetic syngeneic mice and prepared aseptically in HBSS [10]. In one experiment, 
a group of recipients was preirradiated ( $750 \mathrm{rads}) 1$ day prior to transfer of diabetogeneic cells. Diabetic-mouse $T$ cells were prepared using a nylon wool column [29]. Briefly, columns (Fenwal Lab., Deerfield, Ill., USA) were extensively washed with HBSS supplemented with $5 \%$ fetal calf serum and kept for 1 hat $37^{\circ} \mathrm{C}$. Splenocytes $\left(2 \times 10^{7} / \mathrm{ml}\right)$ from overtly diabetic animals were added to the column and incubated for $45 \mathrm{~min}$ at $37^{\circ} \mathrm{C}$; non-adherent $\mathrm{T}$ cells were then eluted. Less than $4 \%$ of B cells were detected, with more than $85 \%$ Thy $-1+$ and $92 \% \mathrm{CD}^{+}$cells. The $\mathrm{CD} 4 / \mathrm{CD} 8$ ratio of $\mathrm{T}$ cells was similar to that in total splenocytes from normal and diabetic donors $(2 / 3 \mathrm{CD} 4+$ and $1 / 3 \mathrm{CD} 8+)$.

\section{Statistical analysis}

The incidence of diabetes was compared between groups by using the chi-square test.

\section{Results}

\section{Effect of thymectomy on the maintenance of T-cell depletion}

Based on evidence that $T$ cells play an important role in protecting NOD mice against the transfer of diabetes by spleen cells from diabetic donors, we evaluated the presence of $\mathrm{CD} 4+\mathrm{T}$ cells in different experimental situations.

We first evaluated T-cell depletion following the injection of monoclonal antibodies directed against $\mathrm{T}$ cells in adult NOD mice. Five-week-old animals received two i.v. injections of purified anti-CD4 plus antiCD8 monoclonal antibodies or saline 1 week apart. Splenocytes were collected 2, 4, 6 and 8 weeks after the last injection. Percentages and absolute numbers of different lymphoid cell subsets were determined by FACS analysis (Table 1 ). No rat kappa-positive cells could be detected 2 weeks post-injection, suggesting the $a b$ sence of monoclonal-coated cells and of residual circulating monoclonal antibodies (data not shown). Consequently in subsequent experiments the transfer of cells from diabetic donors to depleted recipients was performed 2 weeks after the last monoclonal antibody injection. Following this regimen, in normal NOD mice (or sham-thymectomized animals) CD8-depletion was strong and durable (92\% at 2 weeks, $75 \%$ at 4 weeks, $63 \%$ at 6 weeks and $39 \%$ depletion at 8 weeks after the last monoclonal antibody injection compared to salineinjected animals); CD4 + cell depletion was intense but more partial and short-lived ( $65 \%$ at 2 weeks, $15 \%$ at 4 weeks, $14 \%$ at 6 weeks and $4 \%$ at 8 weeks). The efficacy of CD $8+$ T-cell depletion was more pronounced than that of $\mathrm{CD} 4+\mathrm{T}$ cells. A likely hypothesis is that a significant $\mathrm{CD} 4+\mathrm{T}$ cell pool wàs reconstituted from the thymus. This prompted us to evaluate the effect of thymectomy in the regeneration of $\mathrm{T}$ cells in depleted animals.

Following thymectomy at 3 weeks of age, NOD mice were injected with monoclonal antibodies as de- scribed above. Ablation of the thymus prior to monoclonal antibody challenge significantly prolonged duration of CD4 + and CD8 + T-cell depletion. This was particularly clear for CD $8+$ T-cell depletion (94\%, $82 \%, 78 \%$ and $75 \%$ depletion at $2,4,6$ and 8 weeks, respectively after the last injection compared to salinetreated animals). For CD $4+\mathrm{T}$ cells, the depletion was $80 \%, 46 \%, 33 \%$ and $26 \%$ at $2,4,6$ and 8 weeks, respectively compared to controls. Two explanations may be proposed for this difference between CD4 and $\mathrm{CD} 8$ regeneration capacities. First, $\mathrm{CD} 4+\mathrm{T}$ cells may regenerate more rapidly because depletion is only partial. Second, some CD4 + T cells could mature independently of the thymus, as documented for CD8+ $T$ cells in the gut [30]. It is important to note that similar data were obtained when considering absolute $\mathrm{T}$ cell numbers. CD3 or Thy-1 expressions consistently corresponded to the sum of CD4 + and CD8 + T cells, both in percentages and in absolute numbers. $B$ lymphocyte numbers were not significantly modified by anti-T cell monoclonal antibody regimen (data not shown). Altogether, these observations provide strong evidence that anti-CD4 and anti-CD8 treatment essentially operated by depletion of the target cells rather than by modulating CD4 and CD8 molecules.

Since it has been reported that thymectomy at weaning, but not in older animals, may accelerate the onset of diabetes in the NOD model [23], we next evaluated the effect of later thymectomy prior to the injection of T-cell depleting monoclonal antibodies. Ten week-old NOD males thymectomized at 8 weeks of age were injected twice at a 1-week interval with a combination of anti-T cells monoclonal antibodies $(125 \mu$ of each precipitated anti-CD4: GK1.5, anti-CD8: H35-17.2 and anti-Thy-1: $30 \mathrm{H} 12$ ascites). Two weeks after the last monoclonal antibody challenge, Thy. $1+, \mathrm{CD} 4+$ and CD8 + cell subsets were profoundly reduced in percentages and in total numbers of cells $(77 \%, 71 \%$ and $98 \%$ depletion, respectively as compared to sham-thymectomized saline treated recipients), while total numbers of B cells were not significantly modified, which suggests true T-cell depletion rather than antigenic modulation. Furthermore, no monoclonal antibody-coated cells were detectable, as determined by the absence of anti-kappa-stained recipient splenocytes $(0.4 \%$ in treated animals vs $0.3 \%$ in controls; data not shown).

\section{Thymectomy of adult NOD males is required to transfer diabetes}

Because thymectomy in adult male animals has noeffect on the onset of spontaneous diabetes [23] and allows significant T-cell depletion, we decided to use late thymectomized recipients for further transfer experiments.

Of 10 mice thymectomized at 7 weeks of age and having received no monoclonal antibody injection, only one developed diabetes over a 4-month follow-up. 


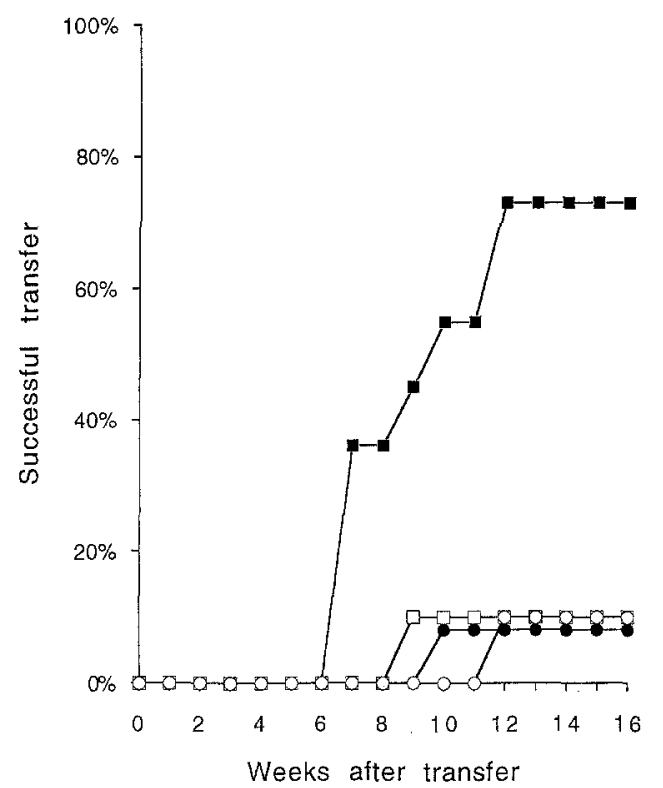

Fig. 1. Twelve recipients thymectomized at 7 weeks of age ( $\boldsymbol{\square})$ and 10 sham-thymectomized recipients $(\square)$ were further depleted with anti-T cell monoclonal antibodies, while 12 thymectomized recipients received saline $(\bullet)$. All were injected at 11 weeks of age with $9 \cdot 10^{6}$ nylon wool-purified $T$ cells collected from overtly diabetic donors. The purity of diabetogeneic T cells is given in Materials and methods and T-cell depletion efficiency is given in the text. One group of 10 thymectomized recipients which did not receive monoclonal antibody treatment or diabetogeneic T cells was included to evaluate the incidence of spontaneous disease $(O)$. The difference at the end of the experiment between the thymectomized T-cell depleted and thymectomized saline-treated groups was significant $(p<0.001)$

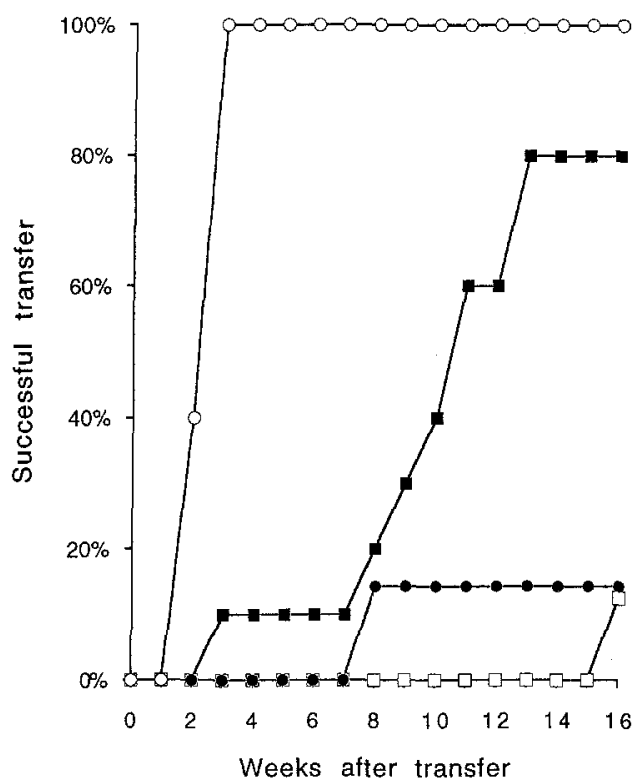

Fig. 2. Ten recipients thymectomized at 9 weeks of age and further depleted with anti-CD4 T cells monoclonal antibodies ( $\boldsymbol{a}$ ), eight thymectomized anti-CD $8 \mathrm{~T}$ cell monoclonal antibody-treated recipients $(\square)$, seven thymectomized saline-treated recipients $(\bullet)$ and five non-depleted sham-thymectomized recipients irradiated (750 rads) the day before transfer (O) were injected at 12 weeks of age with $9 \cdot 10^{6}$ nylon wool-purified T cells from overtly diabetic donors. The purity of diabetogeneic T cells is given in Materials and methods and T-cell depletion efficiency is given in the text. The difference at the end of the experiment between CD4-depleted, saline-treated and CD8-depleted groups were significant $(p<0.01)$
Similarly, of 12 thymectomized non-depleted recipients that received $1010^{6}$ spleen cells from diabetic donors, only one developed diabetes during the same time. By contrast, nine of 12 thymectomized T-cell-depleted recipients developed diabetes upon transfer of diabetic spleen cells (Fig.1). T-cell depletion in sham-thymectomized animals did not permit transfer of IDDM by autoreactive $T$ cells, as only one of 10 recipients became diabetic. Since the transfer of diabetes was observed only when thymectomy was combined with anti-T cell monoclonal antibody injections, it is likely that nonirradiated recipients possess regulatory $\mathrm{T}$ cells which are able to oppose the autoimmune process induced by diabetogenic $\mathrm{T}$ cells. These regulatory $\mathrm{T}$ cells can readily reemerge from the thymus after peripheral $\mathrm{T}$-cell depletion in non-thymectomized recipients.

\section{Regulatory $T$ cells in adult NOD males are CD4+}

To further delineate the role of CD 4 and CD8 T cells in recipient animals, CD4- and CD8-cell depletions were obtained by injecting anti-CD4 $(100 \mu \mathrm{g}$ of purified GK1.5 and $100 \mu \mathrm{l}$ of Y191.1 precipitated ascites) or anti-CD8 (100 $\mu$ of purified H35-17.2 and $100 \mu \mathrm{g}$ of purified 53.6-7) monoclonal antibodies twice at a 1week interval in non-irradiated male NOD mice after thymectomy at 8 weeks of age. CD $4+$ and CD $8+$ T cells were strongly depleted $(84 \%$ and $94 \%$ respectively, data not shown), despite detection in anti-CD8treated animals of $4.5 \% \mathrm{CD} 3+\mathrm{CD} 4-\mathrm{CD} 8-\mathrm{T}$ cells (vs $0.2 \%$ in saline-treated mice), suggesting that a minor fraction of targetted cells modulated their CD8 antigen. This was confirmed, at the time of transfer, by the absence of antibody-recovered cells in all treated recipients, as assessed by the absence of anti-kappa light chain staining (data not shown).

Of $10 \mathrm{CD} 4+\mathrm{T}$ cell-depleted prethymectomized NOD male recipients eight developed diabetes within 4 months after receiving diabetogeneic T cells, compared to one of eight and one of seven thymectomized $\mathrm{CD} 8+$ cell-depleted and non-depleted recipients, respectively ( $p<0.01$, Fig. 2$)$. As a control, all sham-thymectomized preirradiated recipients $(n=5)$ became diabetic within 4 weeks of the transfer. Transfer of diabetes in irradiated animals is as efficient as in CD4depleted non-irradiated recipients $(100 \%$ vs $80 \%$ diabetes respectively, NS), but diabetes appears earlier in the former than in the latter. This difference may be related to the strong but incomplete deletion of $\mathrm{CD} 4+$ $T$ cells in anti-CD4 monoclonal antibody treated recipients. Furthermore, depletion of pancreatic-infiltrating cells is usually more difficult to perform when using monoclonal antibodies.

Our data confirm the involvement of thymus-dependent CD $4+$ T cells in the mechanisms which protect against the transfer of diabetes in non-irradiated adult NOD animals. 


\section{Discussion}

Using a double-transfer experimental procedure, our group and others $[22,31]$ previously reported that the reconstitution of 8-week-old preirradiated NOD male recipients by $\mathrm{CD} 4+$ spleen and/or thymic $\mathrm{T}$ cells from adult non-diabetic counterparts conferred protection against the development of diabetes induced by the injection of spleen cells from diabetic donors. However, the presence of protective CD $4+\mathrm{T}$ cells in the spleen was detectable only within a very narrow time frame (i.e. not after 8-10 weeks of age) although several weeks or months elapsed before most animals developed clinical diabetes [22]. Because double-transfer experiments allow the detection of protective cells in accessible lymphoid compartments and because preirradiation followed by reconstitution of recipients disrupts lymphoid cell distribution, these limitations raise the issue of the actual role of protective $T$ cells in the natural history of diabetes in the NOD mouse.

Therefore, we established a model to characterize regultory cells independently of their transfer into preirradiated recipients. Hypothesizing that $\mathrm{CD} 4+\mathrm{T}$ cells were responsible for blocking the transfer of diabetes in non-irradiated adult recipients, we reasoned that targetting these cells in vivo could substitute for irradiation and allow the disease to develop after injection of spleen cells from diabetic counterparts. Our data confirm that a subset of $\mathrm{CD} 4+\mathrm{T}$ cells present in non-diabetic NOD males allows the blockade of autoreactive T-cells in the NOD mouse model. Interestingly, the model of transfer that was used here allowed direct evaluation of the presence of regulatory $T$ cells independently of their homing in the spleen, which was a limitation in previous co-transfer experiments [22, 31]. We also demonstrate that transfer of diabetes does not require preirradiation of the recipient animals if CD4 + T-cells have been efficiently targetted with monoclonal antibodies. Interestingly, the injection of anti- $T$ cell monoclonal antibody, in the absence of thymectomy, is not sufficient to allow diabetes transfer. The significant reduction of the T-cell compartment in anti-CD4 + T-cell-treated recipients cannot alone explain the ability to transfer the disease by elimination of a bulk of $T$ cells that, by creating a non-specific immune "space", may increase the possibility of rare diabetogenic clones to take. Thymectomy by itself does not significantly diminish T-cell distribution and is more likely to limit reexpansion of regulatory $\mathrm{T}$ cells, responsible for the inhibition of diabetes transfer. On the contrary, we feel that the elimination of a specific regulatory CD4 + T-cell subset in NOD male recipients, which may localize in organs to which access is difficult for the investigator (i.e. the pancreas), is directly responsible for the expansion of autoaggressive $\mathrm{T}$ cells. As this protection is overcome by sublethal irradiation, we propose that these regulatory $\mathrm{CD} 4+\mathrm{T}$ cells are radiosensitive.
The observation that regulatory $\mathrm{CD} 4+\mathrm{T}$ cell clones have not been obtained in the NOD mouse may relate to the fact that cloning studies have mostly been performed in diabetic mice which are unlikely to carry active regulatory cells. Furthermore, such cells could be under-represented in normal and prediabetic animals, or the regulatory function of these cells could be highly dependent on specific environmental factors or interactions between effector cells and their targets. It also cannot be ruled out that regulatory capacities in vivo may be overlooked in vitro by effector cells. The only suppressor clone reported as capable of blocking the transfer of IDDM by T cells from diabetic donors was CD $8+[16]$. The protection afforded by this clone seemed to result from induction of anergy and the clone's ability to secrete an uncharacterized soluble factor interfering with the IL2 receptor on activated T cells [18].

A few recent experimental reports have dealt with regulatory and effector functions mediated by different CD $4+$ subpopulations, and their possible contributions to the development of IDDM. First, it has been shown that reconstitution of thymectomized and irradiated PVG.RT1 ${ }^{u}$ rats with syngeneic CD4+ $\mathrm{OX} 22^{\text {high }} \mathrm{T}$ cells induces IDDM, while reconstitution with whole CD4 $+\mathrm{T}$ cells does not [32]. Furthermore, the diabetogeneic effects of CD4 + OX22 $2^{\text {high }}$ cells can be blocked if rats are further reconstituted with the complementary $\mathrm{CD} 4+\mathrm{OX} 22^{\text {low }}$ subset [32]. The OX22 antibody is specific for the CD45RB antigen [33]. In the rat, CD $4+C D 45 \mathrm{RB}^{\text {high }}$ cells possess similar characteristics to the mouse TH1 cells: they secrete IL-2 and interferon- $\gamma$ but not IL-4. CD $4+$ CD $45 R^{\text {low }}$ present the opposite, $\mathrm{TH} 2$-like, lymphokine profile [34]. These data suggest an autoaggressive potential for $\mathrm{CD} 4+\mathrm{CD} 45 \mathrm{RB}{ }^{\text {high }}$ (TH1-like) T cells, which would be under the control of regulatory $\mathrm{CD} 4+$ CD45RB $^{\text {low }}$ (TH2-like) cells [32]. The second work was developed in the NOD mouse [35]. Here, diabetes is prevented by injection of complete Freund's adjuvant. The complete Freund's adjuvant-induced protection is mediated by CD $4+$ T cells [36]. The authors show that, in the pancreatic infiltrate of complete Freund's adjuvant- protected animals, the CD45RA +/CD45RA - Ratio is two times lower than in nonprotected animals [35]. Furthermore, IL-4 could not be detected in the pancreatic infiltrate of the latter animals, as opposed to complete Freund's adjuvant- protected mice [35]. We have also reported an abnormal bias of CD4 + CD45RA ${ }^{\text {high }} \mathrm{T}$ cells in the NOD mouse

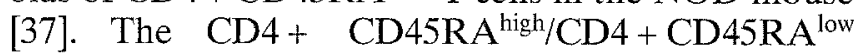
ratio was increased in the thymus, lymph-nodes and mostly among the pancreatic infiltrating cells, and was related to the natural history of IDDM. Interestingly, mature T cells from prediabetic NOD mice are anergic [38]. This unresponsive state is due to the inability of these cells to produce sufficient amounts of IL-4 [39]. Furthermore, this anergy can be completely 
reversed in vitro by IL-4, and injection in vivo of this lymphokine prevents the onset of diabetes [39]. Altogether, these data strongly suggest that some subsets of CD4 $+\mathrm{T}$ cells can mediate regulatory functions that may resemble $\mathrm{TH} 2$ cells. Our data bring evidence for the possible role of such regulatory cells in development of diabetes in vivo. This new model allows the detection of regulatory functions in the NOD mouse and has many advantages compared to the previously reported double-transfer model $[22,31]$.

First, it does not require pre-irradiation of the recipients prior to transfer of diabetogeneic and protective cells, a procedure which dramatically modifies cellularity and haematopoiesis. Furthermore, the necessity in double-transfer experiments to isolate regulatory cells from the defined organ of a donor (i.e. thymus, spleen or lymph-nodes) appears to be a strong limitation, as there is presently no argument favouring such localization of regulatory cells (one may even propose that the most potent regulatory cells constitute the major islet infiltrating T-cell population, essentially when considering adult male NOD mice in which the disease usually never progresses further than mild insulitis). Finally, by testing various monoclonal antibodies specific for markers on $\mathrm{CD} 4+\mathrm{T}$ cells (i.e. CD45R isoforms, IL2 receptor) or specific pharmalogical drugs (e.g. phosphodiesterase inhibitor pentoxifylline, known to act specifically on TH1 cells [40]), our non-irradiated transfer model should enable us to fully delineate the T-cell subset involved in regulatory phenomena without the need to consider its anatomical distribution in the recipient.

Acknowledgements. The authors thank Ms. M. Calise for managing the NOD mice colony, Ms. M.Netter for art work, Ms. A. Reschoeur for helpful secretarial assistance and Ms. D. Broneer for polishing the English. This study was supported by funds from INSERM and P. Sempé is supported by a fellowship from the Ligue Nationale Française Contre le Cancer.

\section{References}

1. Makino S, Kunimoto K, Muraoka Y, Mizushima Y, Katagiri K, Tochino Y (1980) Breeding of a non-obese, diabetic strain of mice. Exp Anim 29: 1-13

2. Hutchings P, Rosen H, O'Reilly L, Simpson E, Gordon S, Cooke A (1990) Transfer of diabetes in mice prevented by blockade of adhesion-promoting receptor on macrophages. Nature 348: 639-642

3. Miyazaki A, Hanafusa T, Yamada K et al. (1985) Predominance of $T$ lymphocytes in pancreatic islets and spleen of prediabetic non obese diabetic (NOD) mice: a longitudinal study. Clin Exp Immunol 60: 622-630

4. Ogawa M, Maruyama T, Hasegawa Tet al. (1985) The inhibitory effect of neonatal thymectomy on the incidence of insulitis in non-obese diabetes (NOD) mice. Biomed Res 6: 103-106

5. Mori Y, Suko M, Okudairo H et al. (1986) Preventive effect of cyclosporin on diabetes in NOD mice. Diabetologia 29: 244-247
6. Kelley VE, Gaulton GN, Hattori M, Ikegami H, Eisenbarth GS, Strom TB (1988) Anti-interleukin 2 receptor antibody suppresses murine diabetic insulitis and lupus nephritis. J Immunol 140: 59-61

7. Hayward AR, Schreiber M (1989) Neonatal injection of CD3 antibody into the non obese diabetic mice reduces the incidence of insulitis and diabetes. J Immunol 143: 1555-1559

8. Sempé P, Bédossa $\mathrm{P}$, Richard MF, Villà MC, Bach JF, Boitard $C$ (1991) Anti- $\alpha \beta$ T cell receptor monoclonal antibody provides an efficient therapy for autoimmune diabetes in non obese diabetic (NOD) mice. Eur J Immunol 21: 1163-1169

9. Pacheco-Silva A, Bastos MG, Muggia RA et al. (1992) Interleukin 2 receptor targeted fusion toxin (DAB486-IL-2) treatment blocks diabetogenic autoimmunity in non-obese diabetic mice. Eur J Immunol 22: 697-702

10. Bendelac A, Carnaud C, Boitard C, Bach JF (1987) Syngeneic transfer of autoimmune diabetes from diabetic NOD mice to healthy neonates. Requirement for both L3T4 + and Lyt $2+$ T cells. J Exp Med 166: 823-832

11. Wicker LS, Miller BJ, Mullen Y (1986) Transfer of autoimmune diabetes mellitus with splenocytes from nonobese diabetic (NOD) mice. Diabetes 35: 855-860

12. Haskins K, Portas M, Bradley B, Wegmann D, Lafferty K (1988) T-lymphocyte clone specific for pancreatic islet antigen. Diabetes 37: 1444-1448

13. Haskins K, Portas M, Bergman B, Lafferty K, Bradley B (1989) Pancreatic islet-specific T-cell clones from nonobese diabetic mice. Proc Natl Acad Sci USA 86: 8000-8004

14. Haskins K, McDuffie M (1990) Acceleration of diabetes in young NOD mice with a CD4 + islet-specific T cell clone. Science 249: 1433-1436

15. Bradley BJ, Wang Y, Lafferty KJ, Haskins K (1990) In vivo activity of an islet-reactive T-cell clone. J Autoimmunity 3 : 449-456

16. Pankewycz O, Strom TB, Rubin-Kelley VE (1991) Islet-infiltrating T cell clones from non-obese diabetic mice that promote or prevent accelerated onset diabetes. Eur J Immunol 21:873-879

17. Nagata M, Yoon J-W (1992) Studies on autoimmunity for Tcell-mediated $\beta$-cell destruction. Distinct difference in $\beta$-cell destrution between CD4 + and CD8 + T-cell clones derived from lymphocytes infiltrating the islets of NOD mice. Diabetes 41: 998-1008

18. Diaz-Gallo C, Moscovitch-Lopatin M, Strom TB, Kelley VR (1992) An anergic, islet infiltrating T-cell clone that suppresses murine diabetes secretes a factor that blocks interleukin 2/interleukin 4-dependent proliferation. Proc Natl Acad Sci USA 89: 8656-8660

19. Bach J-F, Boitard C, Yasunami R, Dardenne M (1990) Control of diabetes in NOD mice by suppressor cells. $J$ Autoimmunity 3 [Suppl]: $97-100$

20. Charlton B, Bacelj A, Slattery RM, Mandel TE (1989) Cyclophosphamide induced diabetes in NOD/Wehi mice: evidence for suppression in spontaneous autoimmune diabetes mellitus. Diabetes 38: 441-447

21. Harada H, Makino S (1984) Promotion of spontaneous diabetes in non-obese diabetes-prone mice by cyclophosphamide. Diabetologia 27: 604-606

22. Boitard C, Yasunami R, Dardenne M, Bach JF (1989) T cell mediated inhibition of the transfer of autoimmune diabetes in NOD mice. J Exp Med 169: 1669-1680

23. Dardenne M, Lepault F, Bendelac A, Bach JF (1989) Acceleration of the onset of diabetes in NOD mice by thymectomy at weaning. Eur J Immunol 19: 889-895

24. Leo O, Foo M, Sachs DH, Samelson LE, Bluestone JA (1987) Identification of a monoclonal antibody specific for murine T3. Proc Natl Acad Sci USA 84: 1374-1378 
25. Pierres M, Goridis C, Golstein P (1982) Inhibition of murine $T$ cell-mediated cytolysis and $T$ cell proliferation by a rat monoclonal antibody immunoprecipitating two lymphoid cell surface polypeptides of 94000 and 180000 molecular weight. Eur J Immunol 12: 60-69

26. Ledbetter JA, Seaman WE (1982) The lyt2, lyt3 macromolecules. Structural and functional studies. Immunol Rev 68 : 197-218

27. Dialynas DP, Quan ZS, Wall KA et al. (1983) Characterization of the murine $\mathrm{T}$ cell surface molecule designated L3T4, identified by monoclonal antibody GK-1.5: similarity of L3T4 to the human T3/T4 molecule and the possible involvement of L3T4 in class II MHC reactivity. J Immunol 131: $2445-2451$

28. Ledbetter J, Rouse R, Micklem S, Herzenberg L (1980) T cell subsets defined by expression of 1yt-1,2,3 and Thy-1 antigens. J Exp Med 152: 280-295

29. Julius MH, Simpson E, Herzenberg LA (1973) A rapid method for the isolation of functional thymus derived murine lymphocytes. Eur J Immunol 3: 645-649

30. Rocha B, von Boehmer H, Guy-Grand D (1992) Selection of intraepithelial lymphocytes with CD $\alpha / \alpha$ co-receptors by self-antigen in the murine gut. Proc Natl Acad Sci USA 89: 5336-5340

31. Hutchings PR, Cooke A (1990) The transfer of autoimmune diabetes in NOD mice can be inhibited or accelerated by distinct cell populations present in normal splenocytes taken from young males. J Autoimmunity $3: 175-185$

32. Fowell D, Mason D (1993) Evidence that the T cell repertoire of normal rats contains cells with the potential to cause diabetes. Characterization of the $\mathrm{CD} 4+\mathrm{T}$ cell subset that inhibits this autoimmune potential. J Exp Med 177: 627-636
33. Spickett GP, Brandon MR, Mason DW, Williams AF, Woollett GR (1983) MRC OX-22, a monoclonal antibody that labels a new subset of $\mathrm{T}$ lymphocytes and reacts with the high molecular weight from of the leukocyte-common antigen. $J$ Exp Med 158: 795-602

34. Powrie F, Fowell D, McKnight AJ, Mason D (1991) Lineage relationships and functions of $\mathrm{CD} 4+\mathrm{T}$-cell subsets in the rat. Res Immunol 42: 54-58

35. Shehadeh NN, LaRosa F, Lafferty KJ (1993) Altered cytokine activity in adjuvant inhibition of autoimmune diabetes. J Autoimmunity 6: 291-300

36. Qin HA, Sadelain MWJ, Hitchon C, Lauzon J, Singh B (1993) Complete Freund's adjuvant-induced T cells prevent the development and adoptive transfer of diabetes in nonobese diabetic mice. J Immunol 150: 2027-2080

37. Sempé P, Ezine S, Marvel J et al. (1993) Role of CD4 + CD45RA + T cells in the development of autoimmune diabetes in the nonobese (NOD) mouse. Int Immunol 5: $479-489$

38. Zipris D, Lazarus AH, Crow AR, Hadzija M, Delovitch TL (1991) Defective thymic T cell activation by concanavalin A and anti-CD3 in autoimmune nonobese diabetic mice. Evidence for thymic $T$ cell anergy that correlates with the onset of insulitis. J Immunol 146: 3763-3771

39. Rapoport MJ, Jaramillo A, Zipris D et al. (1993) Interleukin 4 reverses $T$ cell proliferation unresponsiveness and prevents the onset of diabetes in nonobese diabetic mice. $J$ Exp Med 178: 87-99

40. Rott O, Cash E, Fleischer B (1993) Phosphodiesterase inhibitor pentoxifylline, a selective suppressor of $\mathrm{T}$ helper type- 1 but not type-2 associated lymphokine production, prevents induction of experimental encephalomyelitis in Lewis rats. Eur J Immunol 23: 1745-1751 